\title{
Distinct downstream pathways of caspase-11 in regulating apoptosis and cytokine maturation during septic shock response
}

\author{
SJ Kang ${ }^{1}$, S Wang ${ }^{1,3}$, K Kuida ${ }^{2}$ and J Yuan ${ }^{\star, 1}$ \\ ${ }^{1}$ Department of Cell Biology, Harvard Medical School, 240 Longwood Ave, \\ Boston, MA 02115, USA \\ 2 Vertex Pharmaceuticals, Inc. 130 Waverly St., Cambridge, MA 02139, USA \\ ${ }^{3}$ Current address: Wyeth/Genetics Institute, 200 Cambridge Park Drive, \\ Cambridge, MA 02140, USA \\ * Corresponding author: J Yuan, Department of Cell Biology, Harvard Medical \\ School, 240 Longwood Ave. Boston, MA 02115, USA. Tel: 617 432-4170; \\ Fax: 617 432-4177; E-mail: jyuan@hms.harvard.edu
}

Received 22.2.02; revised 17.4.02; accepted 20.5.02

Edited by G Nunez

\begin{abstract}
Caspase-11 is an essential mediator of septic shock response and caspase-11-deficient mice are resistant to LPS-induced shock. Here we report that LPS-induced caspase- 11 regulates lymphocyte apoptosis by activating both caspase-3 and caspase-7. The activation of caspase-11 preceded that of caspase- 1 and caspases- $3 /-7$, and in the absence of caspase11 , the activation of caspases-3/-7 was significantly reduced. The early activation of caspases-3/-7 by caspase- 11 was not affected by blocking of caspase-1 activity and IL-1 $\beta$ release, implying that caspase-11 activates caspases-3/-7 independently of caspase-1 activation. Furthermore, we show that caspase-11-mediated apoptosis under septic condition is Bidindependent. Our work suggests that the human homologue of caspase-11 may be an effective therapeutic target for treatment of septic shock.

Cell Death and Differentiation (2002) 9, 1115-1125. doi:10.1038/sj.cdd. 4401087
\end{abstract}

Keywords: caspase-1; caspase-3; caspase-7; caspase-11; IL-1 $\beta$

Abbreviations: CARD, caspase recruitment domain; IL, interleukin; LPS, lipopolysaccharides; TUNEL, TdT-mediated dUTP digoxigenin nick-end labeling

\section{Introduction}

Septic shock is a systemic inflammatory disease characterized by fever, hypotension, disseminated intravascular coagulation, multiple organ failure and high rate of fatality. ${ }^{1}$ More than 100000 patients annually die due to septic shock in the US alone. Septic shock is mediated by a complex but common array of immunological cascades, initiated by a variety of pathological conditions such as tissue injury, ischemia-reperfusion, gram-negative and positive bacteria and their endotoxins. Encountering these insults, the body mounts the innate immune response and explosively releases various inflammatory cytokines, which results in a destructive systemic inflammatory reaction. There is substantial evidence that this unbalanced systemic inflammatory reaction is critical for the initial symptoms as well as the eventual organ failure and death of septic patients. ${ }^{2-4}$ On the other hand, analyses of organs and tissues of the patients under septic shock have shown evidence of extensive apoptosis. ${ }^{5-9}$ It has been proposed that the interplay of cytokines and apoptosis may contribute to the devastating consequence of this disease.

A simple animal model of septic shock is to inject LPS intraperitoneally into mice. ${ }^{10-12} \mathrm{~A}$ high dose of LPS mimics septic shock by inducing fever, hypotension, multiple organ failure and death. ${ }^{13}$ The macrophages activated by LPS release various cytokines such as TNF- $\alpha$, IL- 1 , IL-6, IL-8, $\mathrm{IL}-10$, and IL-12. ${ }^{14}$ The critical role of $\mathrm{IL}-1$ in mediating septic shock response has been demonstrated by administrating IL-1Ra, the naturally existing IL-1 antagonist, which significantly reduced lethality of LPS-induced septic shock in rabbits. ${ }^{15}$ The results of clinical studies using IL-1Ra in septic patients, however, have been disappointing. ${ }^{16-18}$ Redundancy and complexity of the inflammatory cascade and heterogeneity of the patient population may account for the disparity between animal models and clinical studies. On the other hand, apoptosis has been proposed as a possible target for treatment of septic shock, as the reports of apoptosis and caspase activation in the patients as well as animal models are accumulating. ${ }^{5,9,19-25}$

Mammalian caspases are a family of 14 tightly regulated cysteine proteases central to execution of apoptosis. Activation of caspases involves proteolytic auto-cleavage facilitated by the formation of an activating complex, as well as cross activation by a different activated caspase resulting in a positive feed forward cascade. ${ }^{26}$ The first caspase activated by a particular apoptotic signal is termed the 'initiator caspase' and often exhibits specificity towards different apoptotic stimuli. For example, cytotoxic agents such as $\gamma$-irradiation or dexamethasone activate caspase-9, which requires the formation of the apoptosome, composed of Apaf-1, and cytochrome $c$ in addition to caspase-9. The activated caspase- 9 in turn activates caspase-3, a major 'executioner' caspase, by proteolytic processing. ${ }^{27}$ On the other hand, Fas receptor signaling activates caspase- $8{ }^{28}$ Caspase-8 activates caspase-3 through direct proteolytic processing in the Fas type I cells but indirectly through Bid and mitochondrial pathway in the Fas type II cells. In the Fas type II cells, the cleavage of Bid by activated caspase8 results in the translocation of truncated Bid to mitochondria to induce mitochondrial damage and release of cytochrome $c$. Cytoplasmic cytochrome $c$ in turn recruits 
Apaf- 1 and caspase- 9 to form the apoptosome and results in activation of caspase- 9 , which subsequently activates caspase-3 through proteolytic processing. ${ }^{29,30}$ In these different apoptotic pathways, activation of caspase-3 is a common downstream event.

Caspases also play an important role in the inflammatory response. Caspase- 1 is directly involved in processing pro$\mathrm{IL}-1 \beta$ into mature $\mathrm{IL}-1 \beta,{ }^{31}$ whereas the activation of caspase-1 is under the control of caspase-11. ${ }^{32}$ The expression of caspase-11 is undetectable in all tissues except intestine in healthy mice and is highly inducible by LPS injection. ${ }^{33}$ Although caspase $-11^{-1-}$ mice do develop initial shock symptoms in response to LPS injection, they are highly resistant to LPS-induced lethality. ${ }^{32}$ Caspase$11^{-/-}$mice exhibited significantly reduced levels of IL-1 $\alpha$ and IL-1 $\beta$ after LPS stimulation. Caspase-11 mediates the activation of caspase-1 by physical interaction. Subsequently it was found that caspase-11 is required for the activation of caspase-3 in apoptosis induced by brain ischemia. $^{34,35}$ Furthermore, caspase-11-deficient oligodendrocytes are partially resistant to cell death induced by experimental autoimmune encephalomyelitis. ${ }^{36}$ These studies suggest that caspase-11 plays a dual role in regulating both cytokine secretion and apoptosis.

Caspase-3 activation has been observed in septic patients and experimental animals. ${ }^{5,25}$ Confirming the adverse contribution of caspase activation and apoptosis to the mortality in the septic shock syndrome, the use of caspase inhibitors markedly improved survival of animal models of septic shock..$^{37,38}$ Since caspase $-11^{-1-}$ mice are resistant to LPS-induced lethality, ${ }^{32}$ these findings raise the strong possibility that caspase-11 may play a pivotal role in regulating apoptosis by mediating the activation of caspase-3 as well. Elucidating the role and activation mechanism of caspase-11 during septic shock will provide an important clue to understand the pathophysiology of septic shock. In this study, we examined the molecular mechanism of caspase-11 action during experimental septic shock induced by direct LPS challenge. We provide spatial, temporal and functional evidence that caspase-11 regulates apoptosis and inflammation in the two downstream pathways that are biochemically separable during septic shock response.

\section{Results}

\section{Caspase-11 is induced in macrophages, B and T cells after LPS-challenge}

Previously it was shown that caspase-11 is highly inducible and activated by LPS, an inducer of septic shock. Thymus, lung, and spleen display high levels of caspase-11 expression after LPS challenge. ${ }^{33}$ The caspase- 11 locus encodes two proteins of 43 and $38 \mathrm{kDa}$, most probably due to alternative starts of translation since the introduction of mutation in Met61 abolished the expression of $38 \mathrm{kDa}$ species (S Kang and $J$ Yuan, unpublished data). We mainly examined spleen in this study for the caspase-11-dependent cell death response, since caspase-11 expression is highest in the spleen after LPS challenge. ${ }^{33}$ To determine the expression pattern of caspase-11 in the spleen after LPS-induced shock, we examined the spleens after LPS challenge by immunohistochemistry. Wild-type mice were intraperitoneally injected with LPS at a dose of $20 \mathrm{mg} / \mathrm{kg}$ body weight. At $12 \mathrm{~h}$ after the injection, spleen was examined by immunohistochemistry using monoclonal anti-caspase-11 antibody. As shown in Figure 1, caspase-11 expression was induced in the cells with lymphocyte appearance mainly in the white pulp of the spleen. Unstimulated wild-type spleen did not show any significant specific staining. To characterize the cell types expressing caspase-11, we sorted splenocytes from LPS-challenged mice according to their cell surface markers and assayed the resulting sorted cells by immunoblot using anti-caspase-11 antibody. Interestingly, B cells in addition to macrophages
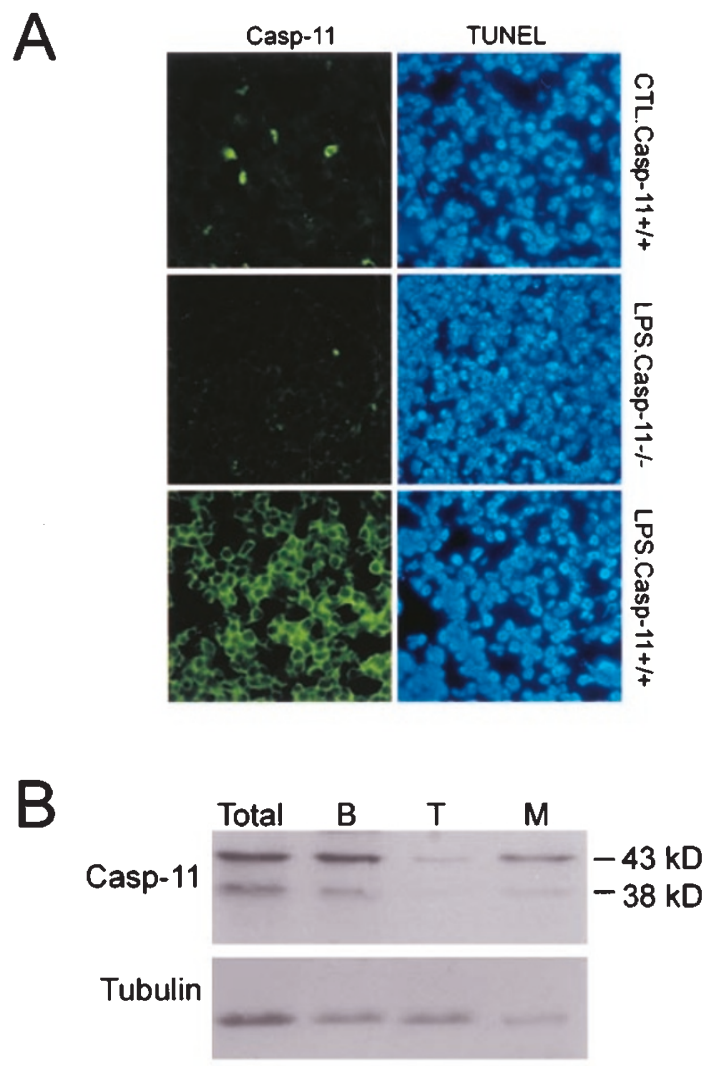

Figure 1 Induction of caspase-11 in splenocytes after LPS challenge. (A) Induction of caspase-11 in spleens after LPS challenge. Caspase-11-deficient $\left(\right.$ Casp $\left.-11^{-/-}\right)$and wild-type littermate control $\left(\right.$Casp- $\left.11^{+/+}\right)$spleen sections ( $5 \mu \mathrm{m}$ thick) from $12 \mathrm{~h}$ LPS challenged $(20 \mathrm{mg} / \mathrm{kg}$ body weight) and unstimulated wild-type control (CTL) mice were stained with 17D9 monoclonal anti-caspase-11 antibody (Casp-11) and counter-stained with Hoechst 33342 dye (Hoechst). Original magnification, $20 \times$. (B) The cell types expressing caspase-11. To examine the cell type of caspase-11 expressing cells in the immune system, RBC-free splenocytes from LPS challenged mice $(20 \mathrm{mg} / \mathrm{kg}$ body weight) were stained with FITC- or PE-coupled antibodies for cell surface markers: anti-B220 for B cells (B), anti-CD3 for T cells (T), and anti-Mac I for macrophages $(M)$ and then sorted according to their cell surface markers using Mo-Flow cell sorter. The sorted cells were then analyzed for the expression of caspase- 11 by immunoblot assay using monoclonal anti-caspase- 11 antibody (Casp-11). Note the expression of caspase-11 in B cells and macrophages. The blot was stripped and reprobed with anti-tubulin antibody for a loading control 
expressed high levels of caspase-11 upon LPS challenge. T cells also expressed caspase-11 after LPS stimulation, albeit at a much lower level (Figure 1B).

\section{Caspase- 3 activation and apoptosis are reduced in the LPS-stimulated caspase- $11^{-1-}$ spleen}

Importantly, caspase-11 $11^{-/}$mice are resistant to LPS shockinduced lethality and the production of proinflammatory cytokines is impaired in these mutant mice. ${ }^{32}$ However, it is unclear whether in this LPS-induced septic shock model, caspase-11 is involved solely in cytokine maturation or in apoptosis as well. Apoptosis has been demonstrated in LPSinduced septic shock mouse model. ${ }^{11}$ Protection from death in caspase- $11^{-1-}$ mice ${ }^{32}$ and the evidence of apoptosis in septic shock ${ }^{37,38}$ led us to examine if caspase-11 plays a role in apoptosis under this condition. We first performed doublestaining of anti-caspase-11 and TUNEL to see if caspase-11 is expressed in apoptotic cells after LPS challenge. Most of the TUNEL-positive cells $(89.7 \% \pm 0.06$, mean \pm S.D.) were also positive for caspase-11 (Figure 2), showing that caspase11 is induced in apoptotic cells. This result suggests that caspase-11 is involved in regulating apoptosis induced by LPS challenge possibly in a cell-autonomous manner.

To examine whether caspase-11 is essential for the septic shock induced apoptosis, we compared the rate of cell death in LPS-challenged caspase- $11^{-/-}$and wild-type spleens. Caspase- $11^{-/-}$and littermate wild-type mice were intraperitoneally injected with LPS and $12 \mathrm{~h}$ later, vehicletreated control and LPS-challenged spleens were processed for TUNEL staining to evaluate apoptotic cell death. As shown in Figure 3, although the basal levels of apoptotic TUNEL positive cells were not different in spleens of wildtype and caspase-11 $11^{-/}$mice, the rate of cell death was markedly lower in the caspase-11 $11^{-/}$spleen than that of wild-type after LPS challenge. As Figure 3B shows, caspase-11 $11^{-/}$spleen displayed about threefold reduction in the TUNEL-positive area when compared to that of wildtype. This suggests that caspase-11 is required for the induction of apoptosis in LPS-induced septic shock.

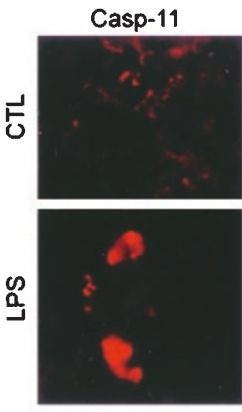

Casp-11
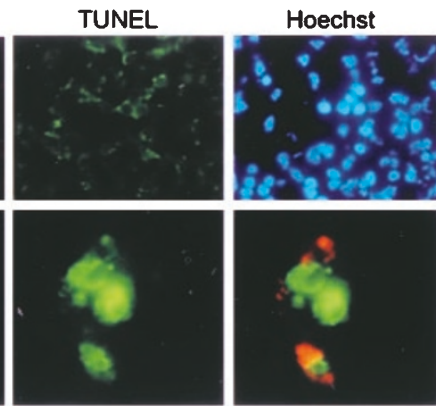

TUNEL

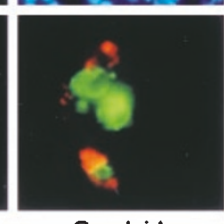

Overlaid
Figure 2 Caspase-11 is expressed in the TUNEL-positive cells. To examine if apoptotic cells are expressing caspase-11, LPS-stimulated (LPS) and unstimulated control (CTL) spleen sections were stained with anti-caspase-11 antibody (Casp-11) and then processed for TUNEL (TUNEL). An overlaid image (C11/TUNEL) shows cells double-positive for caspase-11 and TUNEL. Original magnification of the top panels, $20 \times$; bottom panels, $40 \times$
To investigate the downstream mechanism of the caspase-11-dependent apoptosis, we examined the activation of the downstream effector caspases in the wildtype and caspase-11 $11^{-/}$spleen after LPS injection by immunohistochemistry using $\mathrm{CM} 1$, a rabbit polyclonal antibody against the active form of human caspase-3. ${ }^{39}$ Although CM1 mainly recognizes the active form of caspase-3, it has been reported that this antibody also detects the active form of other homologous executioner caspases, such as caspases- 6 and -7.40 In accordance with the reduction in DNA fragmentation observed in the TUNEL assay, caspase-11 $11^{-/}$spleen showed a significant reduction of the effector caspase activation, as indicated by the significant reduction of CM1 staining (Figure 4). The caspase-11-1- spleen displayed the control level of CM1 staining even after LPS challenge, whereas wild-type spleen showed a marked increase in CM1 staining after LPS stimulation. The reduction of the downstream effector caspase activation in the absence of caspase-11 was confirmed by immunoblot assay using
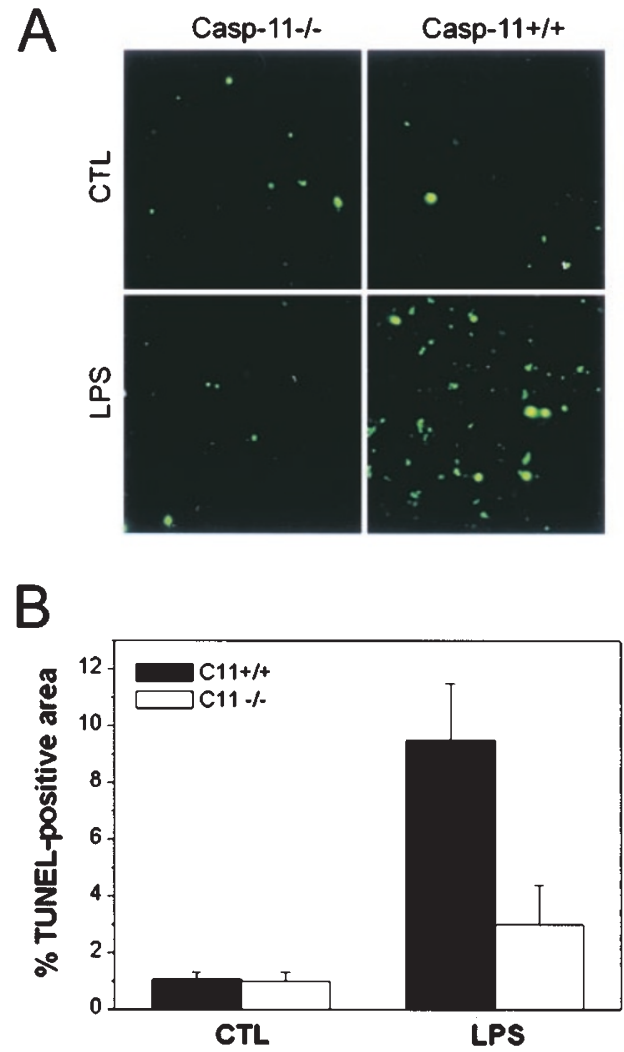

Figure 3 Reduction of apoptosis in caspase- $11^{-/-}$spleens after LPS challenge. (A) Apoptosis in control and LPS stimulated spleens. Caspase-11-

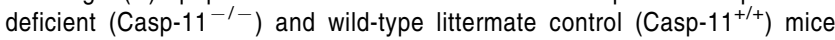
were intraperitoneally injected with LPS $(20 \mathrm{mg} / \mathrm{kg}$ body weight). After $12 \mathrm{~h}$, spleens from LPS challenged mice (LPS) and sterile PBS injected mice (CTL) were processed for TUNEL assay. Note the control level of TUNEL staining in the caspase-11 $11^{-I}$ spleen even after the LPS challenge. Original magnification, $20 \times$. (B) Quantification of the TUNEL-positive area. The rates of TUNEL positive cells were estimated using fluorescence microscopy with the assistance of the Northern exposure software. Means of 10 readings are shown. Error bar represents standard error 
A

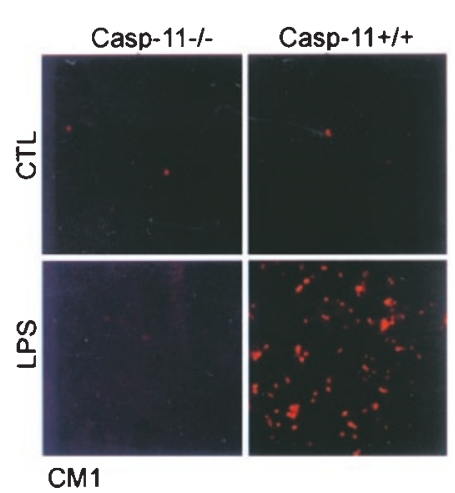

B

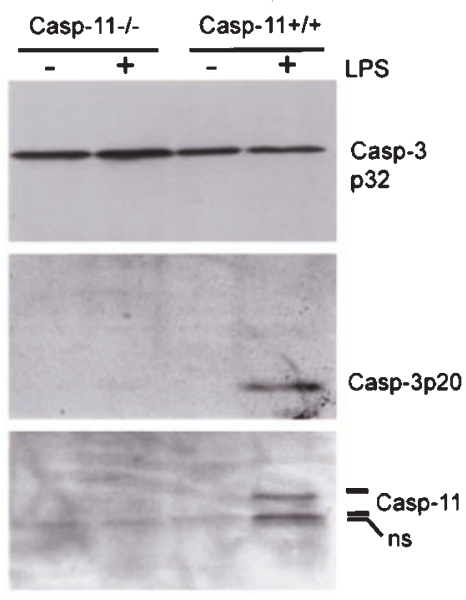

C

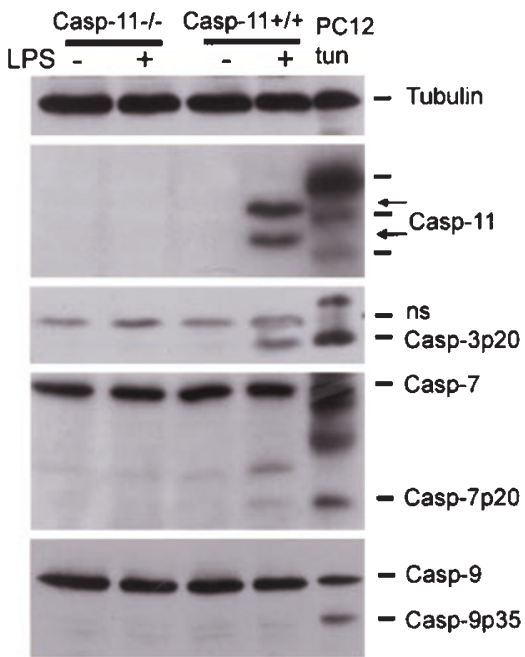

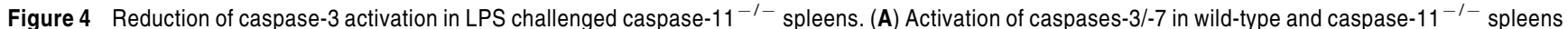

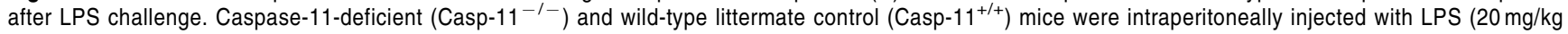
body weight). After $12 \mathrm{~h}$, spleens from LPS challenged mice (LPS) and sterile PBS injected mice (CTL) were processed for immunohistochemistry with CM1, caspase-3p20-specific antibody. Original magnification, $20 \times$. (B) Activation of caspase-3 assayed by Western blot. Caspase- $11^{-1-}$ and littermate wild-type mice were intraperitoneally injected with LPS (LPS +) or sterile PBS (LPS -). At $12 \mathrm{~h}$ after the injection, the spleens were processed for immunoblot assay using antibodies against full-length caspase-3 (Casp-3p32), active form of effector caspases (CM1), and caspase-11 (Casp-11). Note the reduction of the intensity of the CM1-positive p20 band in the caspase-11 $1^{-1-}$ spleen compared to that of wild-type after the LPS challenge. ns; non-specific. (C) Activation of caspase-3/7 and lack of caspase-9 activation in LPS challenged spleens. Spleen lysates from the control (LPS -) and LPS challenged (LPS+) mice were examined for the activation of caspase-3 (casp-3p20), -7 (casp-7p20), and -9 (casp-9p35). As a positive control, the lysates of PC12 cells treated with tunicamycin (100 ng/ml, for $36 \mathrm{~h})$ were loaded (PC12 tun). Note the active form of caspase- 3 and -7 were detected only in the caspase- $11^{+/+}$spleen after the LPS challenge. The active form of caspase-9 was not detected in the spleens. As a loading control, a blot with anti-tubulin (Tubulin) is shown. ns, nonspecific

the same CM1 antibody (Figure 4B). These results suggest that caspase-11 regulates the activation of executioner caspases to induce DNA fragmentation in vivo after the LPS challenge.

Since caspase-3 is a major executioner of apoptotic pathways and known to induce DNA fragmentation during apoptosis by cleaving a specific inhibitor, ICAD, to release the inhibition on a DNase, CAD, ${ }^{41,42}$ we used another active caspase-3-specific antibody (casp-3p20) from a different source (Cell Signaling, Beverly, MA, USA) to confirm whether the activation of caspase-3 is under the regulation of caspase-11. As shown in Figure 4C, caspase3 activation was indeed inhibited in the caspase-11 $1-$ spleen after the LPS challenge, consistent with our conclusion that caspase-11 is required for the activation of caspase-3 under this condition. Tunicamycin-treated PC12 cells were used as a positive control for these experiments.

Since caspase-11 has the same substrate preference as that of caspase- 9 , which is known to activate caspases- 3 and -7 directly by proteolytic cleavage, ${ }^{43,44}$ we examined the status of caspase-7 after the LPS challenge in the caspase-11 mice. As shown in Figure 4C, caspase-7 was also activated in the spleen by LPS challenge and the activation was inhibited in the absence of caspase-11 (Figure 4C). These results suggest that caspase-11 is required for the activation of both caspase-3 and caspase-7 under septic shock conditions.
Since caspase-9 shares the similar substrate preference to that of caspase-11, the activation of caspase- 9 could also explain why both caspase- 3 and -7 are activated under septic shock conditions. Indeed, it has been reported that the cleavage activity of LEHD-p-nitroanilide, an activity attributable to either caspases- 9 or -11 , is specifically increased in thymocytes during sepsis-induced apoptosis. ${ }^{25}$ To ask if caspase- 9 is also activated under septic condition in spleen, we examined the status of caspase- 9 in our model by immunoblot assay, using caspase- 9 antibody that specifically recognizes both full length and activated p35 of caspase-9. While the lysates of PC12 cells treated with tunicamycin $(100 \mathrm{ng} / \mathrm{ml}$ for $36 \mathrm{~h})$ clearly showed the activation of caspase- 9 , as indicated by the appearance of p35 caspase- 9 , the spleen lysates from LPS-treated animals lack any signs of caspase- 9 activation. Thus, it is possible that the LEHD-cleaving activity observed by Tinsley et al. $^{25}$ was due to the activation of caspase-11, rather than caspase- 9 , as was concluded.

These works demonstrated that not only caspase-3 but also caspase-7 are under the control of caspase-11. Furthermore, these results suggest that caspase-11 regulates apoptotic cell death during the septic shock response by simultaneously controlling multiple downstream effector caspases.

We then asked the question of how caspase-11 activates caspases- 3 and -7: caspase-11 may activate caspases-3/-7 directly in a cell-autonomous fashion or 
indirectly through cytokines released from neighboring cells. It is possible that caspase-11 acts cell-autonomously to activate downstream caspases, as in the ischemic brain. ${ }^{34}$ However, proinflammatory cytokines released as a result of caspase-11 activation may promote the activation of downstream caspases indirectly by a noncell-autonomous mechanism, as many of them have been found to be pro-apoptotic under certain conditions. ${ }^{45,46}$ For example, IL-1 $\beta$ has been shown to contribute to cell death under certain conditions. ${ }^{45,47}$ To distinguish between these possibilities, we performed double staining of the stimulated spleens with caspase-11 and CM1. We reasoned that, if caspase-11 activates caspases-3/-7 in cell-autonomous fashion, we should detect caspase-11 and activated caspases-3/-7 in the same cells. Indeed, almost all of the CM1-positive cells were also positive for caspase-11 (Figure 5), supporting the hypothesis that caspase-11 acts in a cell-autonomous manner to induce the activation of caspase-3/-7 after LPS challenge. Taken together, these results are consistent with the hypothesis that caspase-11 activates caspases-3/-7 in a cell-autonomous manner; however, staining alone does not rule out a possible contribution of cytokines in caspases-3/-7 activation mediated by caspase- 11 .

\section{The activation of caspase-11 precedes that of caspases -1 and -3}

The results described above suggest that caspase-11 is required for the activation of caspase-3 in LPS shock-induced cell death in spleens, similar to that of ischemia-induced apoptosis in brain. ${ }^{34}$ This is consistent with the proposal that caspase-11 acts as an initiator caspase, as its specificity is similar to other initiator caspases, such as caspase-8 and

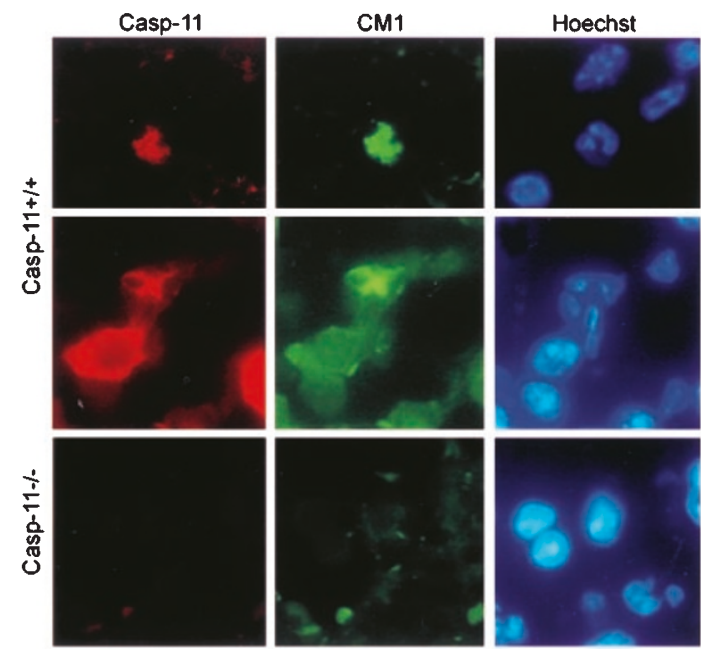

Figure 5 Caspase-11 and active caspases-3/-7 are colocalized in the LPSchallenged spleen. Caspase- $11^{-I-}\left(\mathrm{Casp}-11^{-/-}\right)$and wild-type littermates $\left(\right.$ Casp $\left.-11^{+/+}\right)$mice were injected with LPS $(20 \mathrm{mg} / \mathrm{kg}$ body weight) and the spleens were taken at $12 \mathrm{~h}$ after the challenge. Spleen sections were processed for immunohistochemistry to localize caspase-11 (Casp-11) and active caspases-3/-7 (CM1). Counterstaining with Hoechst 33342 dye (Hoechst) visualizes the nuclei. Original magnification, $40 \times$ caspase-9, that can activate pro-caspase-3. ${ }^{34}$ To further substantiate this possibility, we compared the in vivo time course of caspase-11 activation with that of caspases- 1 and -3 . We reasoned that, if caspase-11 acts as an initiator caspase, its activation should precede the activation of caspases- 1 or -3 . Mice were injected with LPS (20 mg/kg body weight) and the lysates were prepared from the spleen taken at various time points after the injection. Caspase-11 activity was followed by measuring VEHD.amc-cleaving activity in the lysates: caspase-3, by DEVD.amc cleavage and caspase- 1 activation, by ELISA of mature IL-1 $\beta$. As shown in Figure 6 , the increase in VEHD-cleaving activity preceded the DEVD-cleaving activity and $\mathrm{IL}-1 \beta$ release, suggesting caspase- 11 activation occurs before the activation of caspases- 1 and -3 . Notably, the lack of this VEHD-cleavage activity in caspase-11-/- spleen indicates that caspase-11 is indeed responsible for this cleavage activity. Early activation of caspase-11 was confirmed by Western blot assay that shows the appearance of its processed forms as early as $1 \mathrm{~h}$ after the challenge (Figure $6 \mathrm{~B})$. The active fragments of caspase- 3 were detected after $4 \mathrm{~h}$ and increased thereafter (Figure 6B). Taken together, these results further support the hypothesis of the dual role of caspase-11 in acting as an initiator caspase to activate caspase- 3 in apoptosis and caspase- 1 in regulating IL-1 $\beta$ maturation.

\section{Caspase-11 activates caspase-3 independently of caspase-1 activation}

The results shown above suggest that, under certain conditions, caspase-11 is required for the activation of caspase-1 for cytokine maturation and caspase-3 for apoptosis. Therefore, caspase-11 mediates two distinct downstream pathways in regulating cytokine maturation and apoptosis. However, it is not clear whether there is a crosstalk between the caspase- 1 and caspase- 3 pathways. To investigate a possible contribution of proinflammatory cytokines regulated by caspase-11 and caspase-1 to the activation of caspase-3, we examined the effect of inhibition of caspase-1 on caspase- 3 activation. Mice were injected intravenously with 2 or $20 \mu \mathrm{g}$ of ac.YVAD.cmk, an irreversible blocker of caspase-1, before and after the injection of LPS (20 $\mathrm{mg} / \mathrm{kg}$ body weight). At $6 \mathrm{~h}$ after the LPS injection, sera and spleens were taken and examined for plasma levels of mature IL- $1 \beta$ by ELISA and for caspase-3 activation by immunoblot assay. As shown in Figure 7A, the secretion of IL$1 \beta$ was efficiently blocked by ac.YVAD.cmk injection, suggesting the activity of caspase-1 was successfully inhibited in vivo. However, the protein level of caspase-1 remained unchanged when examined by immunoblot assay, suggesting the inhibition of caspase-1 activity did not affect its expression level during the time examined. Even when caspase-1 was inhibited by ac.YVAD.cmk, caspase-11 induction and caspase-3 activation were not inhibited (Figure 7B). The specificity of the peptide inhibitor ac.YVAD.cmk on caspase-1 over caspase-11 was confirmed by in vitro cleavage assay. As shown in Figure 7C, ac.YVAD.cmk inhibited the cleavage of IL-1 $\beta$ by caspase- 1 but not that of PARP by caspase-11 whereas pan-caspase inhibitor zVAD.fmk inhibited both caspase-1 and caspase-11. This 

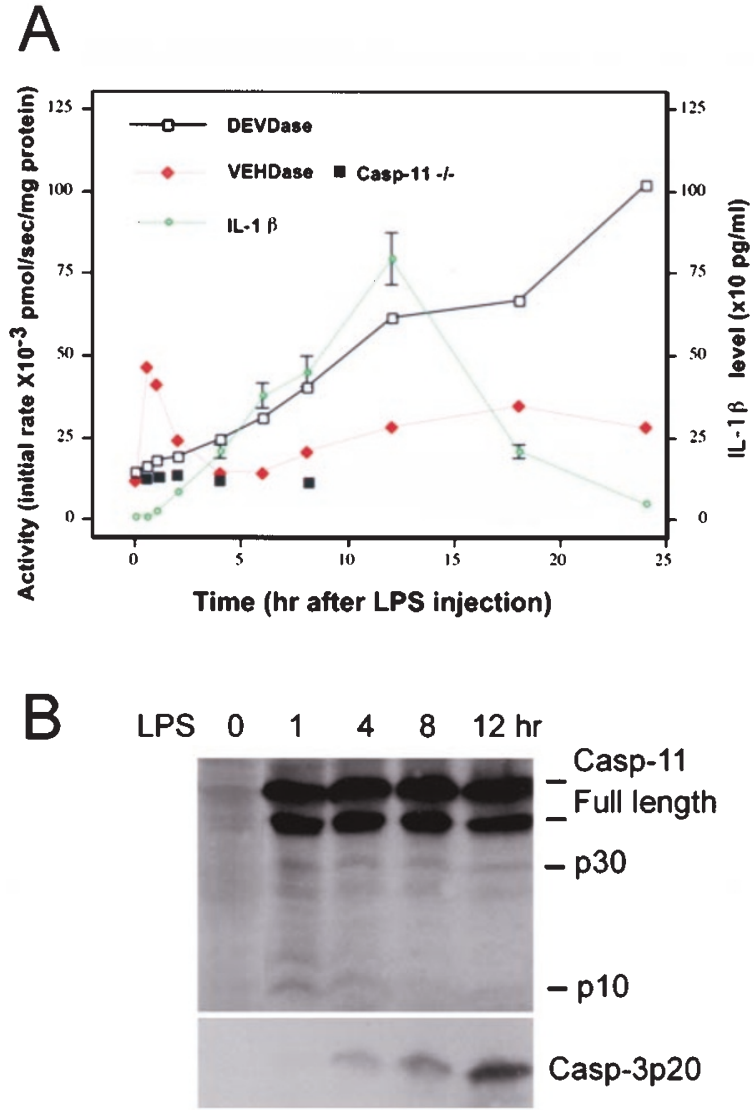

Figure 6 Time course of caspases-1, -3 and -11 activation after LPS challenge. Caspase- 11 mice were injected with LPS $(20 \mathrm{mg} / \mathrm{kg}$ body weight) and spleens were processed for caspase activity assay and immunoblot assay at times indicated. (A) Spleen lysates $(1.5 \mu \mathrm{g} / \mathrm{ml})$ were incubated with ac.DEVD.amc or ac.VEHD.amc to measure the caspase-3-like and caspase11-like activities, respectively. DEVDase (open square) and VEHDase (filled diamond for wild-type and filled square for caspase- $11^{-1-}$ spleens) activities were measured by fluorescence generated as a result of the peptide cleavage, read at $1 \mathrm{~min}$ intervals at $\lambda e x=380 \mathrm{~nm}$ and $\lambda e m=460 \mathrm{~nm}$. The activity was calculated from the initial slope measured for $20 \mathrm{~min}$. For the caspase-1 activity, the serum level of IL-1 $\beta$ (open circle) was measured by ELISA Caspase-11-1- mice were examined only for VEHDase activity (filled square). Note the initial peak of the caspase-11-like enzyme activation, which is absent in the spleen from caspase-11-1- mice. For DEVDase and VEHDase activities, each data point represents a mean of duplicate readings from one mouse. Representative data from two independent experiments are shown. IL-1 $\beta$ level was measured from two mice at each time point for each set of experiment. (B) Spleen lysates were prepared at indicated times after the challenge and immunoblotted against anti-caspase- 11 monoclonal antibody (Casp-11) and CM1 antibody (Casp-3p20)

result suggests that caspase- 11 activates caspase- 3 independently of caspase- 1 activation in the early phase of the shock response.

\section{Absence of Bid does not affect LPS-induced cell death}

Bid is an important mediator of apoptotic signal transduction in Fas type II cells. ${ }^{29,30}$ Since caspase-11 can cleave Bid in vitro (data not shown), we considered the possibility that Bid may be a mediator of caspase-11-induced apoptosis. To examine the contributions of Bid and mitochondrial damage in caspase-11mediated apoptosis, we examined $\mathrm{Bid}^{-/-}$mice for cell death induced by LPS shock. We found that $\mathrm{Bid}^{-/-}$mice were not resistant to LPS shock (20 mg/kg body weight) and died at the same rate as wild-type mice (data not shown). When the spleen and thymus were examined for apoptosis by TUNEL, they showed the same level of cell death as wild-type (Figure $8 A, B$ ). In accordance with the cell death levels, the caspase-3 activation profile in $\mathrm{Bid}^{-/-}$mice was not significantly different from that of wild-type when examined by enzyme activity assay (Figure 8C) and also immunoblot assay (Figure 8D). These results suggest that induction of cell death by caspase- 11 in the spleen and thymus after LPS challenge is independent of Bidmediated mitochondrial damage as in Fas type I cells. This is consistent with our proposal that caspase-11 may activate caspase-3 directly, as we have shown that caspase-11 can proteolytically activate caspase- $3 .^{34}$

\section{Discussion}

The previous work on the role of caspase-11 in brain ischemic injury has led to the proposal that caspase-11 plays a dual role in activating apoptosis and cytokine maturation. ${ }^{34,35}$ The work described here provided further support for this hypothesis by demonstrating the critical role of caspase-11 in activating both caspase-3 and caspase-7 during LPS-induced shock. Furthermore, we established the temporal sequence of caspase-11, caspases-3/-7 and caspase-1 activation, and the independence of caspase- 3 activation from that of cytokine secretion, at least in the early phase of LPS response. We cannot rule out, however, that cytokines may contribute to the cell death observed in the later phase of septic shock as many cytokines released under septic shock condition are both proinflammatory and pro-apoptotic. For example, IL-1 $\beta$ has been found to promote neuronal cell death under ischemic conditions. ${ }^{45,48}$ In addition, TNF $\alpha$, a critical mediator of septic shock induced by LPS, is a strong inducer of both apoptosis and inflammation. ${ }^{49,50}$ The levels of TNF $\alpha$, however, do not seem to be affected in caspase-11 ${ }^{-1-}$ mice (S Wang and J Yuan, unpublished results), suggesting that TNF $\alpha$ may not play a critical role in apoptosis, at least in the early phase of LPS-induced septic shock response.

Strong activation of caspase-11 during LPS induced septic shock response made it possible for us to examine the temporal profile of caspases-1, -3 and -11 activation. Interestingly, caspase-11 activity exhibited a biphasic profile. The first VEHD cleavage peak occurs at $30 \mathrm{~min}$ after LPS injection, noticeably before the increase in caspase- 3 activity and release of mature IL-1 $\beta$. Since the LPS-treated caspase-11 $11^{-/}$spleen lysates did not have this initial peak of VEHD cleavage activity, the early peak of VEHDase activity can indeed be attributed to caspase-11 specifically. This is consistent with caspase-11 playing the initiating role in both apoptosis and inflammatory response during septic shock. It is not clear, however, why caspase11 activity dips after the initial peak, as its expression levels do not seem to change during this time period (S Kang, $S$ Wang and J Yuan, unpublished results). After the dip, caspase-11 activity gradually increased until reaching about $3 / 4$ of the initial peak level. It is possible that the biphasic 
A
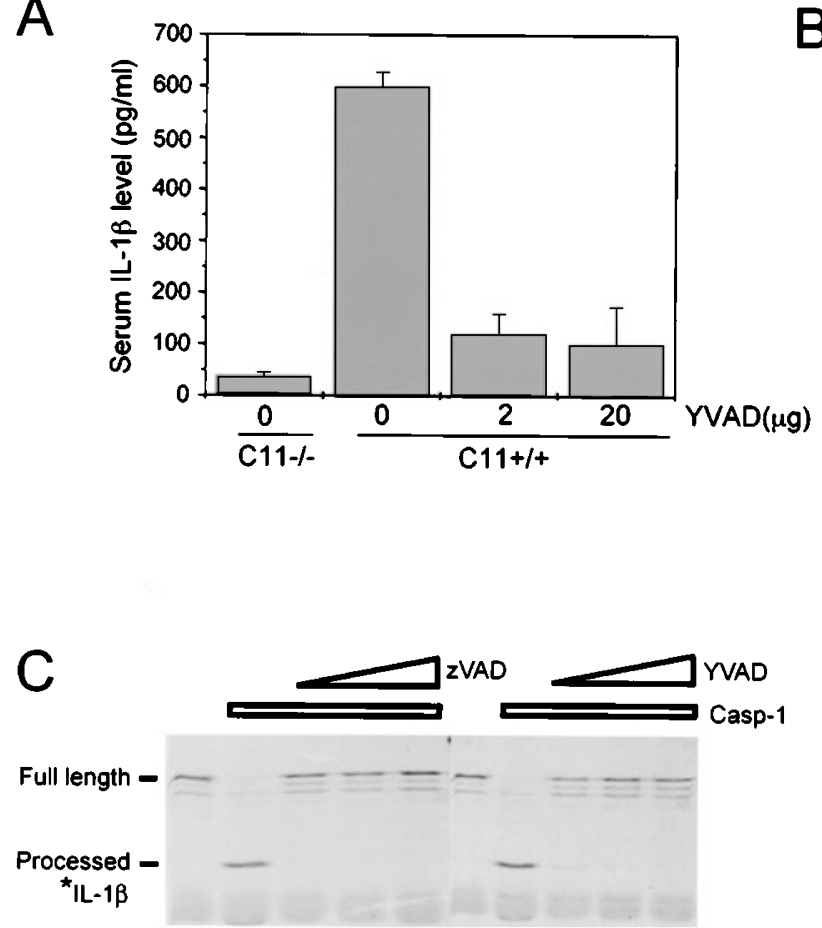

$B$
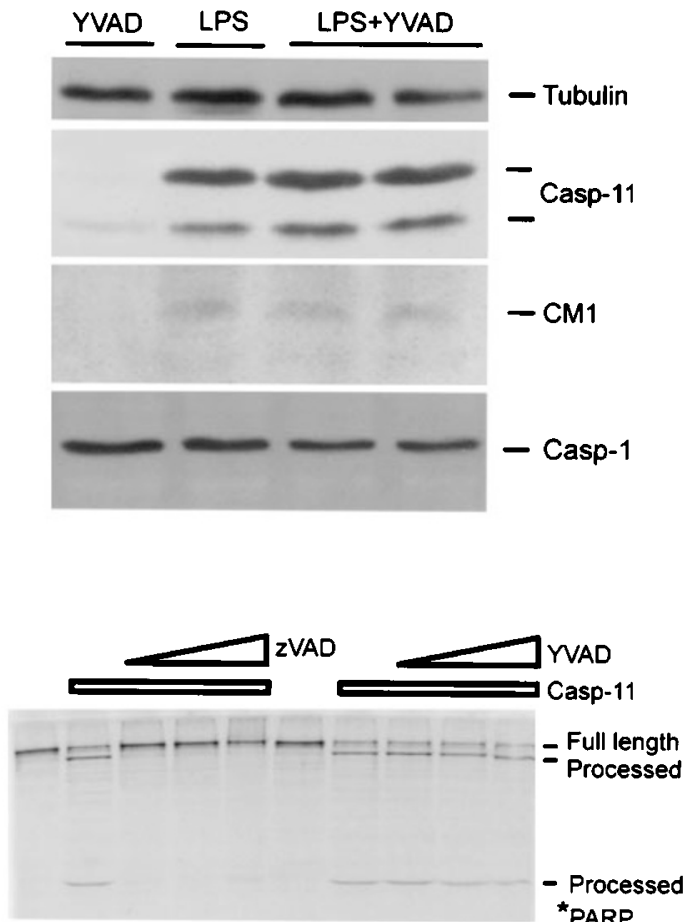

Figure 7 Caspase-11 activates caspases-3/-7 independently of caspase-1 activation. A. Inhibition of IL-1 $\beta$ maturation by ac. YVAD.cmk. To inhibit the activation of caspase-1, an irreversible peptide inhibitor of caspase-1, ac.YVAD.cmk ( $2 \mu \mathrm{g}$ or $20 \mu \mathrm{g}$ per mouse), was injected 30 min prior to and at $0,1,2.5,4 \mathrm{~h}$ after the LPS challenge. At $6 \mathrm{~h}$ after the initial injection, the serum was taken for the measurement of the secreted IL-1 $\beta$ level. Note the reduction of the serum IL-1 $\beta$ level in the wild-type mice $\left(\mathrm{C} 11^{+/+}\right)$almost to that of caspase- $11^{-/-}$mice $\left(\mathrm{C} 11^{-/-}\right)$when ac.YVAD.cmk was injected. (B) Activation of caspases-3/-7 was not inhibited by ac.YVAD.cmk. The spleens from mice injected with ac.YVAD.cmk alone, LPS alone, and LPS plus ac.YVAD.cmk were processed for immunoblot assay using antibodies against caspase-11 (Casp-11), caspase-1 (Casp-1) and active caspase-3/-7 (CM1). The blot was stripped and re-probed with anti-tubulin antibody for a loading control. Note the inhibition of caspase-1 by ac. YVAD.cmk did not affect the activation of caspase-3/-7. C. Specificity of YVAD in the inhibition of caspase-1 but not caspase-11. ${ }^{35}$ S-labeled in vitro translated substrates ( ${ }^{*} \mathrm{IL}-1 \beta$ for caspase-1 and *PARP for caspase-11) were incubated with recombinant caspase-1 (Casp-1) or caspase-11 (Casp-11). Increasing concentrations of pan-caspase inhibitor zVAD.fmk (zVAD) and caspase-1 inhibitor acYVAD.cmk (YVAD) were added (2, 10 and $20 \mu \mathrm{M}$ where indicated) in the cleavage assay to examine the specificity of the inhibitor, ac.YVAD.cmk. Note the ac.YVAD.cmk inhibited caspase-1 but not caspase-11

regulation is due to the non-cell autonomous induction of caspase-11 by cytokines activated by the initial peak of caspase-11 activity. The early peak may reflect the initial induction of caspase-11 directly by LPS through a cell autonomous mechanism and the later phase activity may reflect the induction by proinflammatory cytokines as a positive feedback. The possibility of positive feedback in inducing caspase-11 is strengthened by the observation that the cytokine products of caspase-11/caspase-1 activation, such as IL-1 $\beta$ and IFN- $\gamma$, can each induce the expression of caspase-11 ( $Y$ Jung and $J$ Yuan, unpublished data). It is also possible, however, that the biphasic activity of caspase-11 is the result of cell autonomous regulation, e.g. different activating molecules control the activity of caspase-11 during the different phase of septic shock response. The presence of a CARD motif in its prodomain and the requirement for the interacting molecules in regulating caspase- 1 activation ${ }^{32}$ suggest that there may be caspase-11 CARD-interacting molecules that regulate its activation.

The dual role of caspase-11 in regulating apoptosis and inflammation begs the question of how cells specify which downstream pathway is to be activated. While apoptosis has been proposed to play a role in mediating secretion of cytokines, such as IL-1 $\beta$ that lacks a signal peptide, IL-1 $\beta$ can be released from many types of cells that are stimulated but not undergoing apoptosis. ${ }^{51}$ We can detect a population of cells in LPS-stimulated spleens that are only positive for caspase-11 but not active caspase-3, suggesting that induction of caspase-11 does not lead to an automatic and instantaneous activation of caspase-3. We favor the hypothesis that caspase-11 may activate caspase-1 or caspase-3 in non-overlapping or partially overlapping cell populations. We have shown that caspase11 physically interacts with caspase- 1 but the interaction is not direct. ${ }^{32}$ Thus, it is possible that whether caspase-11 activates caspase-1 or caspase- 3 may depend on the presence of additional protein(s). The presence of these proteins may prevent caspase-11 from directly activating caspase-3 and may facilitate its interaction with caspase- 1 . Thus, the substrate preference of caspase-11 may be altered by the presence of interacting proteins. The initial peak of caspase-11 may act as a self-amplifying signal by regulating the expression of these additional proteins. 


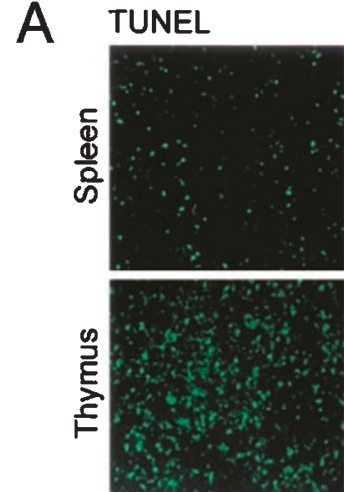

Bid-I-

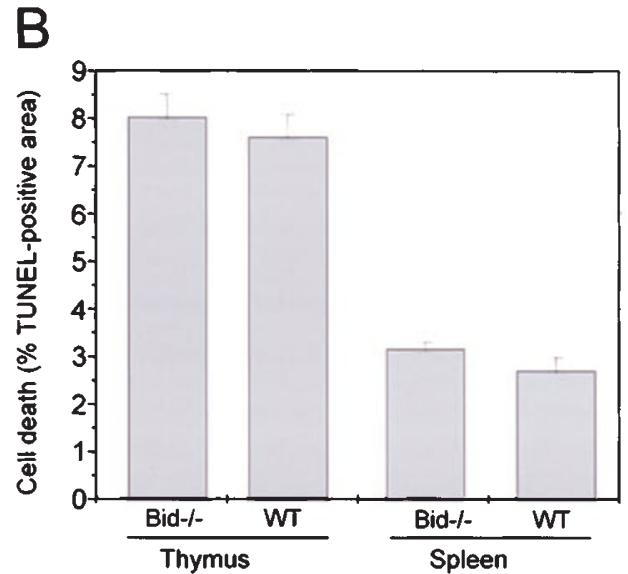

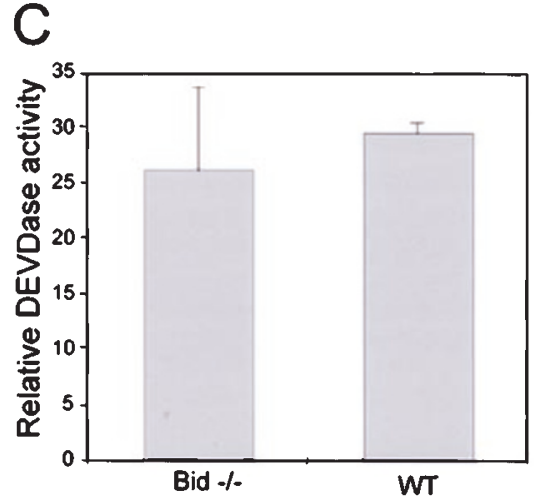

D

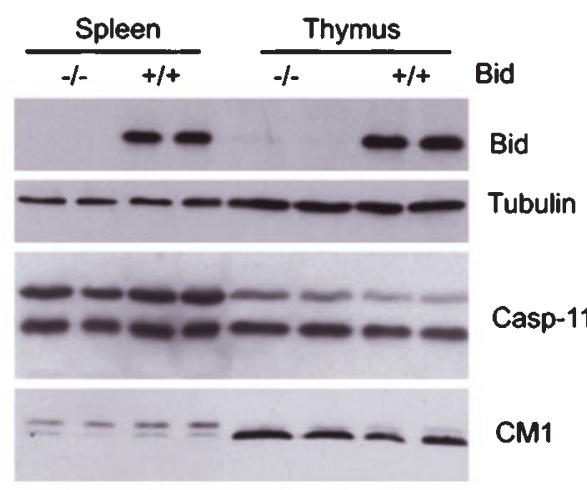

Figure 8 Absence of Bid does not affect LPS-induced cell death or caspases-3/-7 activation in the thymus and spleen. (A) Apoptosis in LPS challenged wild-type and $\mathrm{Bid}^{-1-}$ mice. Wild type (WT) and Bid-deficient $\left(\mathrm{Bid}^{-1-}\right)$ mice were intraperitoneally injected with LPS (20 mg/kg body weight). At $12 \mathrm{~h}$ after the injection, the spleens were taken and processed for TUNEL assay. Original magnification, $10 \times$. (B) The quantification of the TUNEL staining is shown in A. Mean from the readings of 15 samples is shown. Note there is no significant difference in the level of TUNEL-positive area between the wild-type and Bid ${ }^{-1-}$ thymus and spleen. (C) Caspase-3 activation in LPS-challenged wild-type and Bid ${ }^{-1-}$ mice. Caspase-3 activity was measured in the wild-type (WT) and Bid-deficient (Bid ${ }^{-1-}$ ) spleen after the challenge. The spleen lysates $(1 \mu \mathrm{g} / \mu \mathrm{l})$ were incubated with caspase-3 substrate, ac.DEVD.amc $(12.5 \mu \mathrm{M})$ and the cleavage of the peptide was monitored by the generated fluorescence. The DEVDase activity was calculated from the initial slope of the increase in the fluorescence measured for 20 min at 1 min intervals. (D) Induction of caspase-11 and activation of caspases-3/-7 in LPS challenged wild-type and Bid ${ }^{-1-}$ mice. The lysates (50 $\mu \mathrm{g}$ protein) from thymus and spleen of LPS-challenged mice were analyzed by immunoblot assay using antibodies against full-length Bid, caspase-11 (Casp-11) and active caspases-3/-7

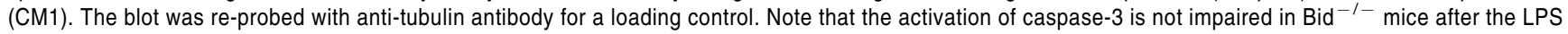
challenge, as examined by both enzyme activity assay and immunoblot assay

$\mathrm{Bcl}-2$ and mitochondrial pathways of apoptosis have been proposed to be involved in apoptosis during septic shock. Haendeler et al. ${ }^{20}$ observed a reduction of $\mathrm{Bcl}-2$ level during septic shock. Overexpression of $\mathrm{Bcl}-2$ in transgenic mice inhibited the apoptosis and inflammatory response during experimental septic shock induced by cecal ligation and puncture (CLP). ${ }^{25,52}$ Unfortunately, the $\mathrm{Bcl}-2$ transgenic mice were in the $\mathrm{C} 3 \mathrm{H}$ HeJ genetic background which is resistant to the lethal effect of endotoxins. Therefore, it is hard to predict whether this conclusion would apply to humans or other animals that are highly sensitive to the lethal effect of endotoxin.

Is apoptosis a detrimental factor for the outcome of the septic shock response? A non-specific caspase inhibitor zVAD.fmk has been shown to inhibit apoptosis and increase survival of mice in sepsis induced by CLP. ${ }^{22}$ zVAD.fmk inhibits both caspase- 1 and caspase-11; and thus, cannot distinguish the effect of apoptosis and inflammatory cytokines. As a way to evaluate the role of apoptosis in the mortality associated with the septic shock, we examined the response of caspase- $3^{-1-}$ mice in the C57BL/6J background to the LPS injection. When the caspase-3-deficient mice were challenged with LPS, they did not show any resistance and demonstrated the same mortality and proinflammatory cytokine release as the wild-type mice, although there is a slight reduction in the cell death when examined by TUNEL assay (our unpublished data). A slight reduction of lymphocyte apoptosis in LPS challenged caspase- $3^{-1-}$ mice has been reported by Hotchkiss et al. ${ }^{38}$ Furthermore, they used caspase inhibitors with a strong preference for caspases-3 and -7 to inhibit apoptosis and improve survival in the CLP model, but the inhibitor had no apparent effect on IL-1 $\beta$ or TNF $\alpha$ release. ${ }^{38}$ Consistent with their results, using YVAD.fmk, a peptide inhibitor selective for caspase- $1,{ }^{31}$ we 
showed that it is possible to dissociate the effect of caspase-3 activation from that of IL-1 $\beta$ secretion. The selectivity of YVAD.fmk, however, is not complete; thus, we may not be able to inhibit caspase-1 selectively in longer term experiment. It is tantalizing to conclude from the work of Hotchkiss ${ }^{31}$ and ours that apoptosis may indeed play a detrimental role in septic shock.

Since pharmacological methods may have intrinsic nonspecificity, the ideal system to test the role of apoptosis in septic shock would be to generate mutant mice that are only defective in caspase-1 but not caspase-11, which will eliminate the production of IL-1 but not TNF $\alpha$. Unfortunately, however, the existing two caspase-1 mutant mouse lines are both defective in caspase- 11 expression as well. ${ }^{34}$ Thus, this question will have to be resolved when these reagents are available. On the other hand, it may not be possible to separate completely the contribution of apoptosis and inflammation to the mortality in septic shock since the two processes are interconnected. Proinflammatory cytokines such as TNF- $\alpha$ and IL-1 $\beta$ can induce apoptotic cell death during the septic shock. ${ }^{10,11,45,53}$ Conversely, apoptotic cell death may contribute to the secretion of mature IL-1 $\beta .^{54,55}$ These results suggest that apoptotic cell death and inflammatory response may be interlinked by positive feedback loops, but the initiation events may be mechanistically separable.

\section{Materials and Methods}

\section{Mice}

The generation of caspase- $11^{-1-}$ mice has been described previously. ${ }^{32} 129 \mathrm{~J} / \mathrm{C} 57 \mathrm{BL} / 6 \mathrm{~J}$ chimeric caspase-11-1- mice were

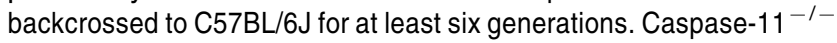
mice are born at the expected Mendelian ratio. Mice used in this study were adults of $8-12$ weeks of age. Mice were maintained in a pathogenfree environment and experiments on mice were conducted according to the protocols approved by the Harvard Medical School Animal Care Committee. Bid ${ }^{-1-}$ mice were kind gifts of Dr. S Korsmeyer (Harvard Medical School, Boston, MA, USA) and described by Yin et al. ${ }^{56}$ Caspase- $3^{-1-}$ mice were described by Takahashi et al. ${ }^{57}$

\section{Septic shock}

Mice were injected intraperitoneally with LPS from E. coli 0111:B4 (Sigma, St. Louis, MO, USA) at a dose of $20 \mathrm{mg} / \mathrm{kg}$. The injected mice were monitored for signs of endotoxemia and sacrificed for tissue collection at designated times after the injection. The serum level of IL$1 \beta$ after the challenge was determined using an ELISA kit for murine IL-1 $\beta$ (R\&D systems, Minneapolis, MN, USA).

For inhibition of mature IL-1 $\beta$ release, irreversible caspase-1 inhibitor ac.YVAD.chloromethylketone (Alexis, San Diego, CA, USA) was injected into the tail vein at an indicated dose and time.

\section{Antibodies}

Generation of monoclonal anti-caspase-11 antibody (17D9) was described previously. ${ }^{33}$ The anti-caspase-7 monoclonal antibody (20F3) was isolated from rats immunized with bacterially expressed caspase-7 protein using conventional protocols. The specificity of this monoclonal antibody against full-length (p35) and activated form (p20) of caspase-7 was reported previously. ${ }^{29}$ Rabbit polyclonal antibody CM1 was made against the $C$ terminus of human caspase-3p20. ${ }^{39}$ The following antibodies were purchased: mouse monoclonal antibody against $\beta$-tubulin (Sigma, St. Louis, MO, USA); rabbit polyclonal antibody against human caspase-3p20 (Cell Signaling, Beverly, MA, USA); mouse monoclonal antibody against human caspase-9 (MBL, Watertown, MA, USA); rat monoclonal antibodies against mouse CD11b (Mac I) coupled with phycoerythrin (PE), mouse CD45R (B220) coupled with $\mathrm{PE}$, and mouse CD3 coupled with fluorescein isothiocyanate (FITC) (Caltag Laboratories, Burlingame, CA, USA).

\section{Immunoblot assay}

For immunoblotting, tissue samples were pulverized in liquid $\mathrm{N}_{2}$ and the resulting tissue powder was solubilized in $0.7 \mathrm{ml}$ of IP lysis buffer (50 mM HEPES (pH 7.5), $150 \mathrm{mM} \mathrm{NaCl}, 1 \mathrm{mM}$ EDTA and 1\% NP40) with protease inhibitors ( $1 \mathrm{mM} \mathrm{PMSF}, 10 \mu \mathrm{g} / \mathrm{ml}$ leupeptin and $5 \mu \mathrm{g} / \mathrm{ml}$ pepstatin). After incubating on ice for $10 \mathrm{~min}$, samples were centrifuged at 13000 r.p.m. in a microfuge at $4^{\circ} \mathrm{C}$ for 20 min. Protein concentration was measured using BioRad protein assay reagent (BioRad Laboratories, Hercules, CA, USA). Sixty micrograms of proteins were subjected to SDS -PAGE on a $15 \%$ gel. Proteins were then transferred onto immobilon-P membrane (Millipore, Bedford, MA, USA) and incubated with blocking solution containing $5 \%$ skim milk in TBST (50 mM Tris, pH 7.5, $150 \mathrm{mM} \mathrm{NaCl}, 0.05 \%$ Tween 20) for $1 \mathrm{~h}$ at RT. The membrane was then incubated with primary antibody in blocking solution at $4^{\circ} \mathrm{C}$ overnight. After washing three times with TBST for 10 min each, the membrane was incubated with horseradish peroxidase (HRP)-conjugated anti-rat or anti-rabbit IgG (Jackson ImmunoResearch, West Grove, PA, USA) for $40 \mathrm{~min}$ at RT. After washing three times, the bound antibody was revealed using the ECL Western blotting reagent (Amersham Life Science, Arlington Heights, IL, USA).

\section{Immunohistochemistry and TUNEL staining}

After LPS challenge, mice were anesthetized and transcardially perfused with cold PBS. The spleens were dissected, embedded in OCT medium and then frozen on top of a block of dry ice. The frozen blocks were kept in $-80^{\circ} \mathrm{C}$ until use. Five-micrometer sections were made in Leica CM3000 cryostat (Leica, Allendale, NJ, USA) and airdried overnight. The sections were then post-fixed in ice-cold acetone for $5 \mathrm{~min}$ and air-dried for more than $1 \mathrm{~h}$. After a brief washing with PBS, endogenous peroxidase activity was quenched by incubating the sections with $0.3 \%$ hydrogen peroxide in PBS for 10 min when TSA signal amplification kit (NEN Life Science Products, Boston, MA, USA) was used for visualization. The sections were then incubated with $10 \%$ normal goat serum in PBS containing $0.1 \%$ Triton X-100 for $1 \mathrm{~h}$ at RT. When biotin-conjugated secondary antibody was used, the samples were first blocked with Vector Biotin/Avidin blocking kit (Vector Laboratories, Burlingame, CA, USA) before incubating with normal goat serum. After blocking, the sections were incubated with drops of anti-caspase-11 monoclonal (undiluted 17D9) and/or anti-caspase 3 p20 (CM1) rabbit polyclonal $(1: 2000)$ antibody in PBS containing $1 \%$ normal goat serum and $0.1 \%$ Triton $\mathrm{X}-100$ at $4{ }^{\circ} \mathrm{C}$ overnight in a humid chamber. The samples were then washed four times with PBS containing $0.1 \%$ Triton $\mathrm{X}-100$ for 5 min each, followed by incubation with secondary antibodies in PBS containing $5 \%$ normal goat serum and $0.1 \%$ Triton X-100 for 30 min at RT. For the detection of caspase11, HRP-conjugated anti-rat goat IgG (Jackson ImmunoResearch) and TSA signal amplification kit were used as directed by the 
manufacturer's protocol. For the detection of caspase-3, appropriate secondary antibodies conjugated with biotin were used. After washing, biotin decorated samples were incubated with Texas red or FITCconjugated streptavidin (Jackson ImmunoResearch) for $30 \mathrm{~min}$ at RT. The tissue sections were then counter-stained with Hoechst 33342 dye $(1 \mu \mathrm{g} / \mathrm{ml}$ in PBS, Sigma, St. Louis, MO, USA) for $10 \mathrm{~min}$ at RT. After washing, slide glass samples were mounted with mounting medium (1 $\mathrm{mg} / \mathrm{ml}$ p-phenylendiamine in PBS containing $90 \%$ glycerol). The samples were examined using Axiovert 135 microscope (Zeiss, Germany) and images were recorded using Northern Exposure software.

For TUNEL assay, samples were fixed with $4 \%$ paraformaldehyde in PBS and post-fixed with ice-cold ethanol/acetic acid $(2: 1)$ solution. After washing with PBS, the samples were treated with proteinase $K$ (20 $\mu \mathrm{g} / \mathrm{ml}$ in PBS) for $15 \mathrm{~min}$ at RT. The samples were then washed with PBS again processed using Apoptag kit (Intergen, Newark, NJ, USA) according to the manufacturer's manual. In case of antibody/ TUNEL double-staining, the digestion with proteinase $\mathrm{K}$ was omitted and TUNEL was followed by antibody staining. The samples were also counter-stained with Hoechst 33342 . To measure the rate of apoptotic cell death, we measured TUNEL-positive cell area from the photographs of the stained samples ( $20 \times$ magnification) using Northern Exposure instead of counting the positive cells since the cell size and density were the same in all samples regardless of the genotype of the mice.

\section{Enzyme activity assay}

To examine the time course of caspase- 3 and -11 activation, the cleavage of ac.DEVD.amc and ac.VEHD.amc was measured in the spleen lysates of the LPS- challenged mice at indicated time points. Mice were injected with $20 \mathrm{mg} / \mathrm{kg}$ body weight of LPS and sacrificed at $0,0.5,1,2,4,6,8,12,18$ and $24 \mathrm{~h}$ after the challenge. The spleens were snap-frozen in the liquid nitrogen and pulverized in the liquid nitrogen-chilled mortar. The resulting powder was lysed in HEPES buffer (50 mM, pH 7.4) containing $150 \mathrm{mM} \mathrm{NaCl}, 1 \mathrm{mM}$ EDTA, $1 \%$ NP40 and protease inhibitor cocktails (Boehringer Mannheim, Germany). After incubating on ice for 15 min with occasional vortex, the samples were spun at 13000 r.p.m. for $15 \mathrm{~min}$ in a microcentrifuge. The supernatant was measured for the protein concentration using BioRad protein assay reagent (BioRad Laboratories, Hercules, $\mathrm{CA})$. Lysates containing $750 \mu \mathrm{g}$ of protein was diluted into HEPES buffer (50 mM, pH 7.4) containing $2 \mathrm{mM}$ DTT and $12 \mu \mathrm{M}$ fluorogenic peptide substrates (ac.DEVD.amc or ac.VEHD.amc) in a total volume of $300 \mu \mathrm{l}$. Fluorescence as a result of caspase activation was measured at $10 \mathrm{~s}$ intervals using Aminco Bowman Series 2 Luminescence spectrometer $(\lambda \mathrm{ex}=380 \mathrm{~nm}, \lambda \mathrm{em}=460 \mathrm{~nm})$. The slopes were calculated from the increasing fluorescence using the software MicroCal Origin and used as relative caspase activity.

\section{In vitro cleavage assay}

In vitro translation of ${ }^{35} \mathrm{~S}$-labeled proteins (IL-1 $\beta$ and PARP) was done using TNT-coupled transcription/translation kit (Promega, Madison, WI, USA). ${ }^{35}$ S-labeled proteins were incubated with $1 \mu \mathrm{g}$ of recombinant caspase-1 (pHZ2) or caspase-11 (pS15) ${ }^{34}$ in $50 \mu \mathrm{M}$ Tris- $\mathrm{HCl}(\mathrm{pH} 8.0)$ buffer containing $0.5 \mathrm{mM}$ EDTA, $0.5 \mathrm{mM}$ sucrose, $10 \mathrm{mM}$ DTT and protease inhibitor cocktails with or without peptide caspase inhibitor zVAD.fmk or ac.YVAD.cmk. The reaction was terminated by addition of SDS protein sample buffer and then analyzed by SDS-PAGE and autoradiography.

\section{Acknowledgements}

We thank Mike Boyce and Dr. Roberto Sanchez-Olea for critical reading of the manuscript, Dr. Stanley Korsmeyer for providing Bid-deficient mice, Dr. Anu Srinivasan for providing CM1 antibody, Dr. Toshiyuki Nakagawa for helpful advice, Hong Zhu for generating monoclonal antibodies and Christian Mahlke for technical assistance in mouse genotyping. This work was supported by a grant from the National Institute of Aging (AG12859) to J Yuan.

\section{References}

1. Stone R (1994) Search for sepsis drugs goes on despite past failures. Science 264: $365-367$

2. Baue AE (1997) Multiple organ failure, multiple organ dysfunction syndrome, and systemic inflammatory response syndrome. Why no magic bullets? Arch. Surg. 132: $703-707$

3. Antonelli M (1999) Sepsis and septic shock: pro-inflammatory or antiinflammatory state? J. Chemother 11: 536-540

4. Kox WJ, Volk T, Kox SN and Volk HD (2000) Immunomodulatory therapies in sepsis. Intensive Care Med. 26: S124-S128

5. Hotchkiss RS, Swanson PE, Freeman BD, Tinsley KW, CobbJP, MatuschakGM, Buchman TG and Karl IE (1999) Apoptotic cell death in patients with sepsis, shock, and multiple organ dysfunction. Crit. Care Med. 27: 1230-1251

6. Adrie C, Bachelet M, Vayssier-Taussat M, Russo-Marie F, Bouchaert I, AdibConquy M, Cavaillon JM, Pinsky MR, Dhainaut JF and Polla BS (2001) Mitochondrial membrane potential and apoptosis peripheral blood monocytes in severe human sepsis. Am. J. Respir. Crit. Care Med. 164: 389-395

7. Oberholzer A, Oberholzer C, Minter RM and Moldawer LL (2001) Considering immunomodulatory therapies in the septic patient: should apoptosis be a potential therapeutic target? Immunol Lett. 75: 221-224

8. Oberholzer A, Oberholzer C and Moldawer LL (2001) Sepsis syndromes: understanding the role of innate and acquired immunity. Shock 16: 83-96

9. Oberholzer C, Oberholzer A, Clare-Salzler Mand Moldawer LL (2001) Apoptosis in sepsis: a new target for therapeutic exploration. Faseb J. 15: 879-892

10. Zhang YH, Takahashi K, Jiang GZ, Kawai M, Fukada M and Yokochi T (1993) In vivo induction of apoptosis (programmed cell death) in mouse thymus by administration of lipopolysaccharide. Infect Immun. 61: 5044-5048

11. Haimovitz-Friedman A, Cordon-Cardo C, Bayoumy S, Garzotto M, McLoughlin M, Gallily R, Edwards 3rd CK, Schuchman EH, Fuks Z and Kolesnick R (1997) Lipopolysaccharide induces disseminated endothelial apoptosis requiring ceramide generation. J. Exp. Med. 186: 1831-1841

12. Remick DG, Newcomb DE, Bolgos GL and Call DR (2000) Comparison of the mortality and inflammatory response of two models of sepsis: lipopolysaccharide vs. cecal ligation and puncture. Shock 13: 110-116

13. Morrison DC, Vukajlovich SW, Ryan JL and Levin J (1987) Structural requirements for gelation of the Limulus amebocyte lysate by endotoxin. Prog. Clin. Biol. Res. 231: 55-73

14. Tracey KJ and Lowry SF (1990) The role of cytokine mediators in septic shock. Adv. Surg. 23: 21-56

15. Ohlsson K, Bjork P, Bergenfeldt M, Hageman R and Thompson RC (1990) Interleukin-1 receptor antagonist reduces mortality from endotoxin shock. Nature 348: $550-552$

16. Fisher Jr CJ, Dhainaut JF, Opal SM, Pribble JP, Balk RA, Slotman GJ, Iberti TJ, Rackow EC, Shapiro MJ, Greenman RL, Reines HD, Shelly MP, Thompson BW, LaBrecque JF, Catalano MA, Knaus WA and Sadoff JC (1994) Recombinant human interleukin 1 receptor antagonist in the treatment of patients with sepsis syndrome. Results from a randomized, double-blind, placebo-controlled trial. Phase III rhIL-1 ra Sepsis Syndrome Study Group. Jama. 271: 1836-1843

17. Opal SM, Fisher Jr CJ, Dhainaut JF, Vincent JL, Brase R, Lowry SF, Sadoff JC, Slotman GJ, Levy H, BalkRA, Shelly MP, Pribble JP, LaBrecque JF, Lookabaugh J, Donovan H, Dubin H, Baughman R, Norman J, DeMaria E, Matzel K, Abraham E and Seneff M (1997) Confirmatory interleukin-1 receptor antagonist trial in severe sepsis: a phase III, randomized, double-blind, placebo-controlled, multicenter trial. The Interleukin-1 Receptor Antagonist Sepsis Investigator Group. Crit. Care Med. 25: 1115-1124 
18. Zeni F, Freeman B and Natanson C (1997) Anti-inflammatory therapies to treat sepsis and septic shock: a reassessment. Crit. Care Med. 25: 1095-1100

19. Ayala A, Herdon CD, Lehman DL, Ayala CA and Chaudry IH (1996) Differential induction of apoptosis in lymphoid tissues during sepsis: variation in onset, frequency, and the nature of the mediators. Blood. 87: 4261-4275

20. Haendeler J, Messmer UK, Brune B, Neugebauer E and Dimmeler S (1996) Endotoxic shock leads to apoptosis in vivo and reduces Bcl-2. Shock 6: 405-409

21. Hotchkiss RS, Swanson PE, Cobb JP, Jacobson A, Buchman TG and Karl IE (1997) Apoptosis in lymphoid and parenchymal cells during sepsis: findings in normal and T- and B-cell-deficient mice. Crit. Care Med. 25: 1298-1307

22. Hotchkiss RS, Tinsley KW, Swanson PE, Chang KC, Cobb JP, Buchman TG, Korsmeyer SJ and Karl IE (1999) Prevention of lymphocyte cell death in sepsis improves survival in mice. Proc. Natl. Acad. Sci. USA 96: 14541-14546

23. Isogai E, Isogai H, Kubota T, Fujii N, Hayashi S, Indoh T, Takagi S, Miura H and Kimura K (1998) Apoptosis of lymphocytes in mice administered lipopolysaccharide from Leptospira interrogans. Zentralbl Veterinarmed [B]. 45: 529537

24. Moldawer LL (1999) Organ apoptosis in the septic patient: a potential therapeutic target? Crit. Care Med. 27: 1381-1382

25. Tinsley KW, Cheng SL, Buchman TG, Chang KC, Hui JJ, Swanson PE, Karl IE and Hotchkiss RS (2000) Caspases $-2,-3,-6$, and -9 , but not caspase-1, are activated in sepsis-induced thymocyte apoptosis. Shock 13: 1-7

26. Cryns V and Yuan J (1998) Proteases to die for. Genes Dev. 12: 1551-1570

27. Li P, Nijhawan D, Budihardjo I, Srinivasula SM, Ahmad M, Alnemri ES and Wang X (1997) Cytochrome $c$ and dATP-dependent formation of Apaf-1/caspase- 9 complex initiates an apoptotic protease cascade. Cell 91: 479-489

28. Scaffidi C, Fulda S, Srinivasan A, Friesen C, Li F, Tomaselli KJ, Debatin KM Krammer PH and Peter ME (1998) Two CD95 (APO-1/Fas) signaling pathways. EMBO J. 17: 1675-1687

29. LiH, Zhu H, Xu CJ and Yuan J (1998) Cleavage of BID by caspase 8 mediates the mitochondrial damage in the Fas pathway of apoptosis. Cell 94: 491-501

30. Luo X, Budihardjol,Zou H, Slaughter C and Wang X (1998)Bid, a Bcl2 interacting protein, mediates cytochrome $c$ release from mitochondria in response to activation of cell surface death receptors. Cell 94: 481-490

31. Thornberry NA, Bull HG, Calaycay JR, Chapman KT, Howard AD, Kostura MJ Miller DK, Molineaux SM, Weidner JR, Aunins J and et al. (1992) A novel heterodimeric cysteine protease is required for interleukin- 1 beta processing in monocytes. Nature 356: 768-774

32. Wang S, Miura M, Jung YK, Zhu H, Li E and Yuan J (1998) Murine caspase-11, an ICE-interacting protease, is essential for the activation of ICE. Cell 92: 501-509

33. Wang S, Miura M, Jung Y, Zhu H, Gagliardini V, Shi L, Greenberg AH and Yuan J (1996) Identification and characterization of Ich-3, a member of the interleukin1 beta converting enzyme (ICE)/Ced-3 family and an upstream regulator of ICE. J. Biol. Chem. 271: 20580-20587

34. Kang SJ, Wang S, Hara H, Peterson EP, Namura S, Amin-Hanjani S, Huang Z, Srinivasan A, Tomaselli KJ, Thornberry NA, Moskowitz MA and Yuan J (2000) Dual role of caspase-11 in mediating activation of caspase-1 and caspase-3 under pathological conditions. J. Cell Biol. 149: 613-622

35. Shibata M, Hisahara S, Hara H, Yamawaki T, Fukuuchi Y, Yuan J, Okano H and Miura M (2000) Caspases determine the vulnerability of oligodendrocytes in the ischemic brain. J. Clin. Invest. 106: 643-653

36. Hisahara S, Yuan J, Momoi T, Okano H and Miura M (2001) Caspase-11 mediates oligodendrocyte cell death and pathogenesis of autoimmunemediated demyelination. J. Exp. Med. 193: 111-122

37. Kawasaki M, Kuwano K, Hagimoto N, Matsuba T, Kunitake R, Tanaka T, Maeyama T and Hara N (2000) Protection from lethal apoptosis in lipopolysaccharide-induced acute lung injury in mice by a caspase inhibitor. Am. J. Pathol. 157: 597-603

38. Hotchkiss RS, Chang KC, Swanson PE, Tinsley KW, Hui JJ, Klender P Xanthoudakis S, Roy S, Black C, Grimm E, Aspiotis R, Han Y, Nicholson DW and Karl IE (2000) Caspase inhibitors improve survival in sepsis: a critical role of the lymphocyte. Nat. Immunol. 1: 496-501
39. Srinivasan A, Roth KA, Sayers RO, Shindler KS, Wong AM, Fritz LC and Tomaselli KJ (1998) In situ immunodetection of activated caspase-3 in apoptotic neurons in the developing nervous system. Cell Death Differ. 5: 1004-1016

40. Zheng TS, Hunot S, Kuida K, Momoi T, Srinivasan A, Nicholson DW, Lazebnik Y and Flavell RA (2000) Deficiency in caspase-9 or caspase-3 induces compensatory caspase activation. Nat. Med. 6: 1241-1247

41. Enari M, Sakahira H, Yokoyama H, Okawa K, Iwamatsu A and Nagata S (1998) A caspase-activated DNase that degrades DNA during apoptosis, and its inhibitor ICAD. Nature 391: 43-50

42. Sakahira H, Enari M and Nagata S (1998) Cleavage of CAD inhibitor in CAD activation and DNA degradation during apoptosis. Nature 391: 96 - 99

43. Srinivasula SM, Ahmad M, Fernandes-Alnemri T and Alnemri ES (1998) Autoactivation of procaspase- 9 by Apaf-1-mediated oligomerization. Mol. Cell. 1: $949-957$

44. Slee EA, Harte MT, Kluck RM, Wolf BB, Casiano CA, Newmeyer DD, Wang HG Reed JC, Nicholson DW, Alnemri ES, Green DR and Martin SJ (1999) Ordering the cytochrome c-initiated caspase cascade: hierarchical activation of caspases-2, -3, -6, -7, -8, and -10 in a caspase-9- dependent manner. J. Cell Biol. 144: $281-292$

45. Friedlander RM, Gagliardini V, Rotello RJ and Yuan J (1996) Functional role of interleukin 1 beta (IL-1 beta) in IL-1 beta-converting enzyme-mediated apoptosis. J. Exp. Med. 184: 717-724

46. Rothwell N, Allan S and Toulmond S (1997) The role of interleukin 1 in acute neurodegeneration and stroke: pathophysiological and therapeutic implications. J. Clin. Invest. 100: 2648-2652

47. Troy CM, Stefanis L, Prochiantz A, Greene LA and Shelanski ML (1996) The contrasting roles of ICE family proteases and interleukin-1beta in apoptosis induced by trophic factor withdrawal and by copper/zinc superoxide dismutase down-regulation. Proc. Natl. Acad. Sci. USA 93: 5635-5640

48. Boutin H, LeFeuvre RA, Horai R, Asano M, Iwakura Y and Rothwell NJ (2001) Role of IL-1alpha and IL-1beta in ischemic brain damage. J. Neurosci. 21:5528 5534

49. Wallach D, Varfolomeev EE, Malinin NL, Goltsev YV, Kovalenko AV and Boldin MP (1999) Tumor necrosis factor receptor and Fas signaling mechanisms. Annu. Rev. Immunol. 17: 331-367

50. Venters HD, Dantzer R and Kelley KW (2000) A new concept in neurodegeneration: TNFalpha is a silencer of survival signals. Trends Neurosci. 23: $175-180$

51. Dinarello CA (1994) Interleukin-1. Adv. Pharmacol. 25: 21-51

52. Hotchkiss RS, Swanson PE, Knudson CM, Chang KC, Cobb JP, Osborne DF, Zollner KM, Buchman TG, Korsmeyer SJ and Karl IE (1999) Overexpression of $\mathrm{Bcl}-2$ in transgenic mice decreases apoptosis and improves survival in sepsis. J. Immunol. 162: 4148-4156

53. Kato Y, Morikawa A, Sugiyama T, Koide N, Jiang GZ, TakahashiK and Yokochi T (1995) Role of tumor necrosis factor-alpha and glucocorticoid on lipopolysaccharide (LPS)-induced apoptosis of thymocytes. FEMS Immunol. Med. Microbiol. 12: 195-204

54. Lizard G, Lemaire S, Monier S, Gueldry S, Neel D and Gambert P (1997) Induction of apoptosis and of interleukin-1beta secretion by 7beta-hydroxycholesterol and 7-ketocholesterol: partial inhibition by Bcl-2 overexpression. FEBS Lett. 419: 276-280

55. Miwa K, Asano M, Horai R, Iwakura Y, Nagata S and Suda T (1998) Caspase 1 independent IL-1beta release and inflammation induced by the apoptosis inducer Fas ligand. Nat. Med. 4: 1287-1292

56. Yin XM, Wang K, Gross A, Zhao Y, ZinkelS, Klocke B, Roth KA and Korsmeyer SJ (1999) Bid-deficient mice are resistant to Fas-induced hepatocellular apoptosis. Nature 400: 886-891

57. Takahashi K, Kamiya K, Urase K, Suga M, Takizawa T, Mori H, Yoshikawa Y, Ichimura K, Kuida K and Momoi T (2001) Caspase-3-deficiency induces hyperplasia of supporting cells and degeneration of sensory cells resulting in the hearing loss. Brain Res. 894: 359-367 